\title{
Effect of Ag Content on the Microstructure and Magnetic Properties of Grain-oriented Silicon Steels
}

\author{
Yong WAN, ${ }^{1) *}$ Weiqing $\mathrm{CHEN}^{2)}$ and Qingqing $\mathrm{ZHAO}^{31}$ \\ 1) School of Metallurgical Engineering, Anhui University of Technology, Ma'anshan, Anhui, 243002 China. \\ 2) State Key Laboratory of Advanced Metallurgy, University of Science and Technology Beijing, Beijing, 100083 China. \\ 3) School of International Education, Anhui University of Technology, Ma'anshan, Anhui, 243002 China.
}

(Received on August 29, 2015; accepted on November 26, 2015)

\begin{abstract}
The effect of $\mathrm{Ag}$ content in the range of $0-0.026 \mathrm{wt} \%$, on the precipitates, microstructure, texture and magnetic properties of five grain-oriented electrical steels have been studied. A small quantity of Ag atoms with content less than $0.005 \mathrm{wt} \%$ only existed in the form of solid solution and promoted the nucleation rate of grain with $\{111\}$ orientation on the grain boundary during decarburizing process. However, when Ag level rised to $0.012 \mathrm{wt} \%$, some supersaturated Ag atoms precipitated from the matrix and in the form of single Ag-rich particles which inhibited the nucleation of the grains with (111) orientation and promoted the nucleation of grains with other orientation, such as Goss-orientation, during decarburizing process. The average grain size of decarburized bands decreased continuously as Ag content rised from 0 to 0.026 $w t \%$. Compared to those final recrystallized bands with other Ag contents, the final recrystallized bands containing $0.012 \mathrm{wt} \% \mathrm{Ag}$ obtained slightly larger average grain size. As Ag content rised from 0 to 0.026 $w t \%$, magnetic flux density $\left(B_{8}\right)$ firstly dramatically decreased and then abruptly increased, nevertheless, core loss $\left(P_{1.7 / 50}\right)$ firstly slightly increased and then obviously decreased in final recrystallized bands. Final recrystallized bands with $0.026 \mathrm{wt} \% \mathrm{Ag}$ obtained the best magnetic properties, whose core loss and magnetic flux density were $1.140 \mathrm{~W} / \mathrm{kg}$ and $1.467 \mathrm{~T}$, respectively.
\end{abstract}

KEY WORDS: Ag content; grain-oriented silicon steel; grain size; texture; magnetic property.

\section{Introduction}

Grain-oriented silicon steel is one of the most important functional materials used as lamination cores in various transformers and large generators, in which high magnetic induction and low core loss are required. ${ }^{1-6)}$ The increment in permeability and reduction in core loss of grainoriented silicon steel are closely related to the sharpness of $\{110\}<001>$ preferred orientation, also known as Goss texture. $^{7-9)}$ This extremely high accumulation to the Gossorientation is mainly achieved by adjusting the fine precipitates referred to as inhibitors or the elements segregating on the grain boundaries, which could suppress the growth of the primary-recrystallized grains which are out of the Gossorientation, and thereby, promote the preferential growth of grains which are in the Goss-orientation. ${ }^{10-15)}$ Thus, inhibitors play an important role in improving magnetic properties of grain-oriented silicon steel. Particles such as MnS, AlN, $\mathrm{Cu}_{2} \mathrm{~S}$, and $\mathrm{Sn}$, etc. ${ }^{16-24)}$ have been reported to be effective for grain growth inhibition. Mishra ${ }^{25}$ demonstrated that the increase in copper content had been beneficial to the magnetic properties of $3 \% \mathrm{Si}-\mathrm{Fe}$. $\mathrm{Liu}^{26)}$ found that adding $\mathrm{Sn}$ or $\mathrm{Sb}$ to the high induction oriented silicon steel could refine its primary and secondary recrystallize grain size and

\footnotetext{
* Corresponding author: E-mail: wanyong0729@163.com DOI: http://dx.doi.org/10.2355/isijinternational.ISIJINT-2015-498
}

enhance the texture component of $\{110\}<001>$. However, very few investigations are concentrated on the role of $\mathrm{Ag}$ precipitates in grain-oriented electrical steels. Saito ${ }^{27)}$ discovered that the presence of impurity elements, such as Ag, was to develop the strong (110)[001] texture by secondary recrystallization. Imai et al. ${ }^{28,29)}$ indicated the growthinhibiting effect of $\mathrm{Ag}$ was greater than $\mathrm{Cu}$ and $\mathrm{Ag}$ element had strong mutual chemical affinity with sulfur and tended to form $\mathrm{Ag}_{2} \mathrm{~S}$ precipitates. Takashima ${ }^{30)}$ found that small quantities of $\mathrm{Ag}$ existed as $\mathrm{Ag}$-rich phases or $\mathrm{Ag}_{2} \mathrm{~S}$ precipitates in high silicon electrical steels. These facts stimulated us to systematically study the effect of Ag content on the precipitates, microstructure, texture and magnetic properties of grain-oriented electrical steels.

\section{Materials and Experimental Procedures}

The materials used for this study are five types of grainoriented electrical steels with different levels of Ag, the chemical composition of each is listed in Table 1. The qualified steels were melted in a vacuum induction furnace and were cast into $50 \mathrm{~mm} \times 50 \mathrm{~mm} \times 80 \mathrm{~mm}$ ingots. The ingots were reheated to $1350^{\circ} \mathrm{C}$ for $2 \mathrm{~h}$ and hot-rolled out in 2.3-mm thick bands. To simulate the coiling conditions, the hot-rolled bands were maintained at $720^{\circ} \mathrm{C}$ for $1 \mathrm{~h}$ in a box resistance furnace, followed by air-cooling. After a normalizing annealing at $1100^{\circ} \mathrm{C}$ for $4.5 \mathrm{~min}$, all of the 
bands were pickled and uniformly cold rolled to a thickness of $0.30 \mathrm{~mm}$ with a total reduction of $87 \%$. The cold-rolled sheets were cut into $30 \mathrm{~mm}$ width $\times 300 \mathrm{~mm}$ length coupons in a longitudinal direction parallel to the rolling direction. Then, the specimens were heated up to $850^{\circ} \mathrm{C}$ and soaked for $4 \mathrm{~min}$ in a wet atmosphere with dew point at $45^{\circ} \mathrm{C}$ for decarburization. Secondary recrystallization annealing was carried out in a $20 \% \mathrm{~N}_{2}$ and $80 \% \mathrm{H}_{2}$ mixed atmosphere with a heating rate of $15^{\circ} \mathrm{C} / \mathrm{h}$ up to $1200^{\circ} \mathrm{C}$ and soaked for $9 \mathrm{~h}$ under a $100 \% \mathrm{H}_{2}$ atmosphere for purification.

After secondary recrystallization, magnetic properties of the specimens were measured by a single strip tester. Magnetic flux density was measured at a magnetizing force of $800 \mathrm{~A} / \mathrm{m}\left(B_{8}\right)$, and iron loss was measured at $1.7 \mathrm{~T}$ induction and $50 \mathrm{~Hz}\left(P_{1.7 / 50}\right)$. For decarburized and final recrystallized specimens, one hundred field images were taken of each specimen and the type, size and precipitate density of $\mathrm{Ag}$ precipitates in the specimens were observed and analyzed by a ZEISS ULTRA 55 field scanning electron microscope (FSEM) coupled with EDS for elemental analysis. Precipitate density is here defined as the total precipitates number divided by the total counted area. After decarburizing or secondary recrystallization annealing, HKL electron backscatter diffraction (EBSD) was conducted to observe grain orientations and sizes in each of the specimens, and ten field images were taken of each specimen. The density of grain with given orientation is calculated and defined as the number of grains with given orientation divided by the total counted area. Grain sizes were measured by the intercept method based on ASTM standard E-112. For decarburized and final recrystallized specimens, a Siemens D-5000 X-ray

Table 1. The chemical compositions of the investigated steels $(\mathrm{wt} \%)$.

\begin{tabular}{cccccccc}
\hline Steel & $\mathrm{C}$ & $\mathrm{Si}$ & $\mathrm{Mn}$ & $\mathrm{S}$ & $\mathrm{P}$ & $\mathrm{Als}$ & $\mathrm{Ag}$ \\
\hline 1 & 0.032 & 3.043 & 0.090 & 0.003 & 0.014 & 0.035 & 0 \\
2 & 0.034 & 3.060 & 0.091 & 0.003 & 0.013 & 0.038 & 0.003 \\
3 & 0.037 & 3.042 & 0.090 & 0.003 & 0.014 & 0.038 & 0.005 \\
4 & 0.031 & 3.036 & 0.090 & 0.003 & 0.013 & 0.039 & 0.012 \\
5 & 0.036 & 3.050 & 0.088 & 0.003 & 0.014 & 0.035 & 0.026 \\
\hline
\end{tabular}

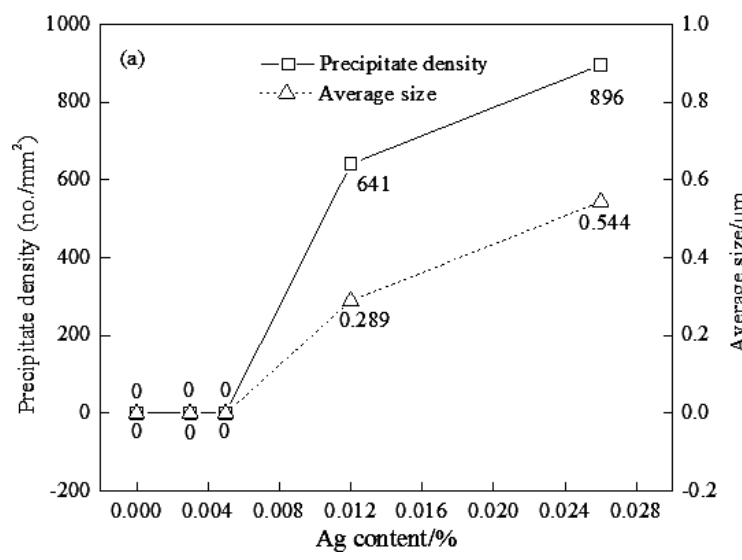

diffractometer with a texture attachment was employed to measure their $\{110\},\{200\}$ and $\{211\}$ pole figures. The diffractometer, employing Mo radiation, was operated at 40 $\mathrm{kV}$ and $25 \mathrm{~mA}$. Three pole figures were used to calculate the orientation distribution by orientation distribution function (ODF) software with $\mathrm{L}=22$.

\section{Results and Discussion}

\subsection{Types, Size and Precipitate Density of Ag Precipi- tates}

Quantitatively, the precipitate density and size of Agbearing precipitates in decarburized and final recrystallized specimens of the investigated steels is shown in Fig. 1. Figures 2(a)-2(c) are typical bright-field FSEM images showing the morphology, distribution and elemental analysis of Ag-bearing precipitates in the decarburized and final recrystallized bands. It can be seen that very few Ag-bearing precipitates exist in the decarburized and final recrystallized bands with $\mathrm{Ag}$ contents of $0 \mathrm{wt} \%, 0.003$ $\mathrm{wt} \%$ and $0.005 \mathrm{wt} \%$ and a large number of fine Ag-bearing precipitates appear in the decarburized and final recrystallized bands with $\mathrm{Ag}$ contents of $0.012 \mathrm{wt} \%$ and $0.026 \mathrm{wt} \%$ (see Fig. 1(a)). Both precipitate density and average size of Ag-bearing precipitates in the decarburized and final recrystallized bands with a $\mathrm{Ag}$ level of $0.026 \mathrm{wt} \%$ is slightly larger than those in the decarburized and final recrystallized bands with a Ag level of $0.012 \mathrm{wt} \%$ due to the increased $\mathrm{Ag}$ content. Moreover, the average size of Ag-bearing precipitates in final recrystallized bands is slightly larger than that in decarburized bands. As shown in Figs. 2(a)-2(c), the minor element Ag is mainly in the form of single Ag-rich particle with size less than $0.8 \mu \mathrm{m}$ in the decarburized and final recrystallized bands with $\mathrm{Ag}$ contents of $0.012 \mathrm{wt} \%$ and $0.026 \mathrm{wt} \%$. Single Ag-rich particles are approximately spherical and nonuniform throughout the matrix, and it is hard to see $\mathrm{Ag}_{2} \mathrm{~S}$ precipitate in the matrix. However, there are still a few existed in the form of composite $\mathrm{Ag}-\mathrm{MnS}$ and $\mathrm{Ag}-\mathrm{AlN}$ precipitates in the investigated steels. As discussed above, it is postulated that $\mathrm{Ag}$ atoms only exist in the form of solid solution with Ag content less than 0.005 $\mathrm{wt} \%$, nevertheless, some supersaturated $\mathrm{Ag}$ atoms will precipitate from the matrix and in the form of single Ag-rich particles when Ag level rises to $0.012 \mathrm{wt} \%$ in grain-oriented

Fig. 1. Effect of Ag content on the precipitate density and average size of Ag-bearing precipitates: (a) decarburized bands; (b) final recrystallized bands. 
silicon steel. With further increasing $\mathrm{Ag}$ content, the amount of the Ag-rich particles increases significantly and Ag-rich particle coalescence appears to occur. Although Ag atoms are less prone to form $\mathrm{Ag}_{2} \mathrm{~S}$ precipitates in the grain-oriented silicon steel, Ag-rich particles can act as nucleation site of $\mathrm{AlN}$ and $\mathrm{MnS}$ precipitates and form composite precipitates with larger size.

\subsection{Grain Sizes of Decarburized and Final Recrystal- lized Bands}

Figure 3 shows the crystal orientation maps of microstructures in longitudinal cross section of the cold-rolled bands after decarburizing. The crystal orientation maps of microstructures in the surface layer of final recrystallized bands are shown in Fig. 4. Figure 5 shows the density of grain with given orientation in decarburized and final recrystallized bands. Table 2 lists the average grain sizes of decarburized and final recrystallized bands. It is illustrated from Fig. 3 and Table 2 that the average grain size of decar- burized bands decreases continuously with increasing $\mathrm{Ag}$ content. The average grain sizes of decarburized bands with $\mathrm{Ag}$ contents in the range of $0-0.026 \mathrm{wt} \%$ fabricated under same process conditions ranges from 13 to $43 \mu \mathrm{m}$. Moreover, compared to the equiaxed grains in decarburized bands with $\mathrm{Ag}$ contents of $0 \mathrm{wt} \%, 0.003 \mathrm{wt} \%$ and $0.005 \mathrm{wt} \%$, the equiaxed grains in decarburized bands with $\mathrm{Ag}$ contents of $0.012 \mathrm{wt} \%$ and $0.026 \mathrm{wt} \%$ distributed more uniformly over the whole longitudinal cross sections and smaller difference in the grain size can be seen from the surface to the interior. This is because a large number of Ag-rich particles in decarburized bands with $\mathrm{Ag}$ contents of $0.012 \mathrm{wt} \%$ and $0.026 \mathrm{wt} \%$ increase their resistance to deformation during hot rolling and thereby make the deformation more uniform throughout the thickness of the hot rolled bands. Moreover, the fine and dispersed Ag-rich particles strongly impede the growth of the ferrite grains by pinning the grain boundaries and therefore, the grains in decarburized bands with $\mathrm{Ag}$ contents of $0.012 \mathrm{wt} \%$ and $0.026 \mathrm{wt} \%$ are smaller and more
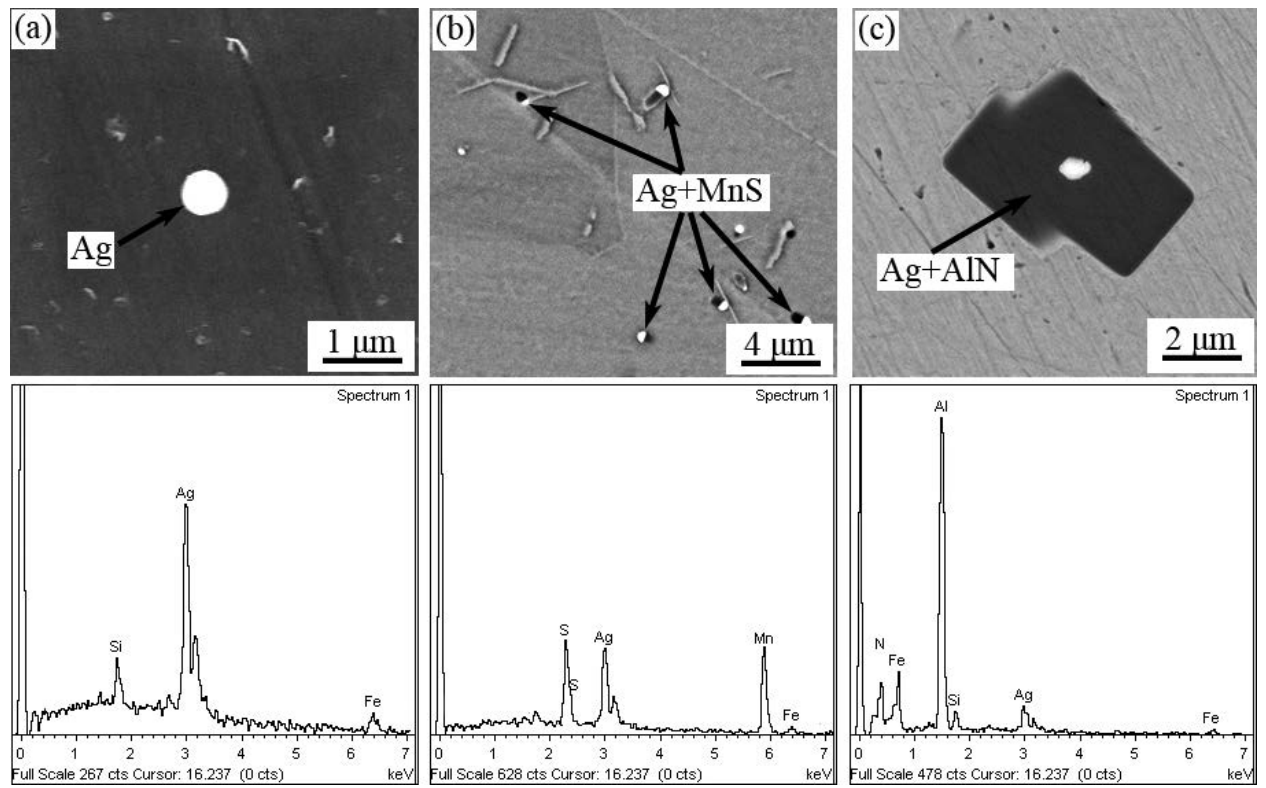

Fig. 2. Morphologies and energy spectrum analysis of Ag-bearing precipitates: (a) Ag; (b) $\mathrm{Ag}-\mathrm{MnS}$; (c) $\mathrm{Ag}-\mathrm{AlN}$.

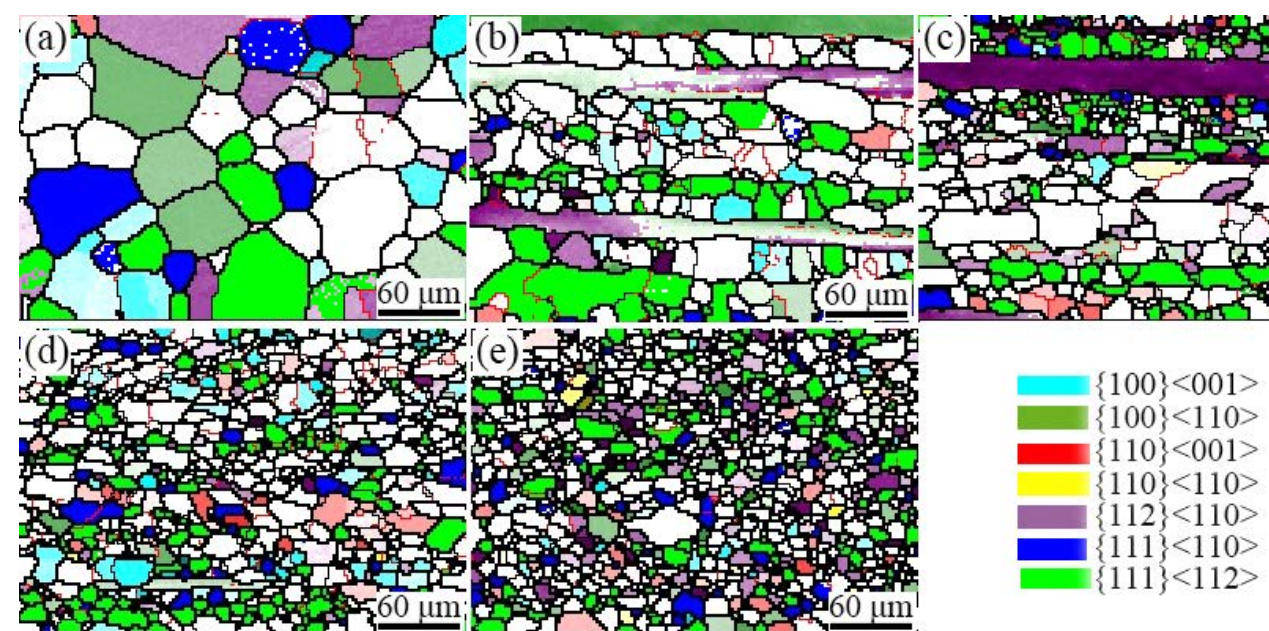

Fig. 3. Crystal orientation maps of decarburized microstructures at different Ag content: (a) 0 wt $\%$; (b) 0.003 wt \% ; (c) $0.005 \mathrm{wt} \%$; (d) $0.012 \mathrm{wt} \%$; (e) $0.026 \mathrm{wt} \%$. (Online version in color.) 

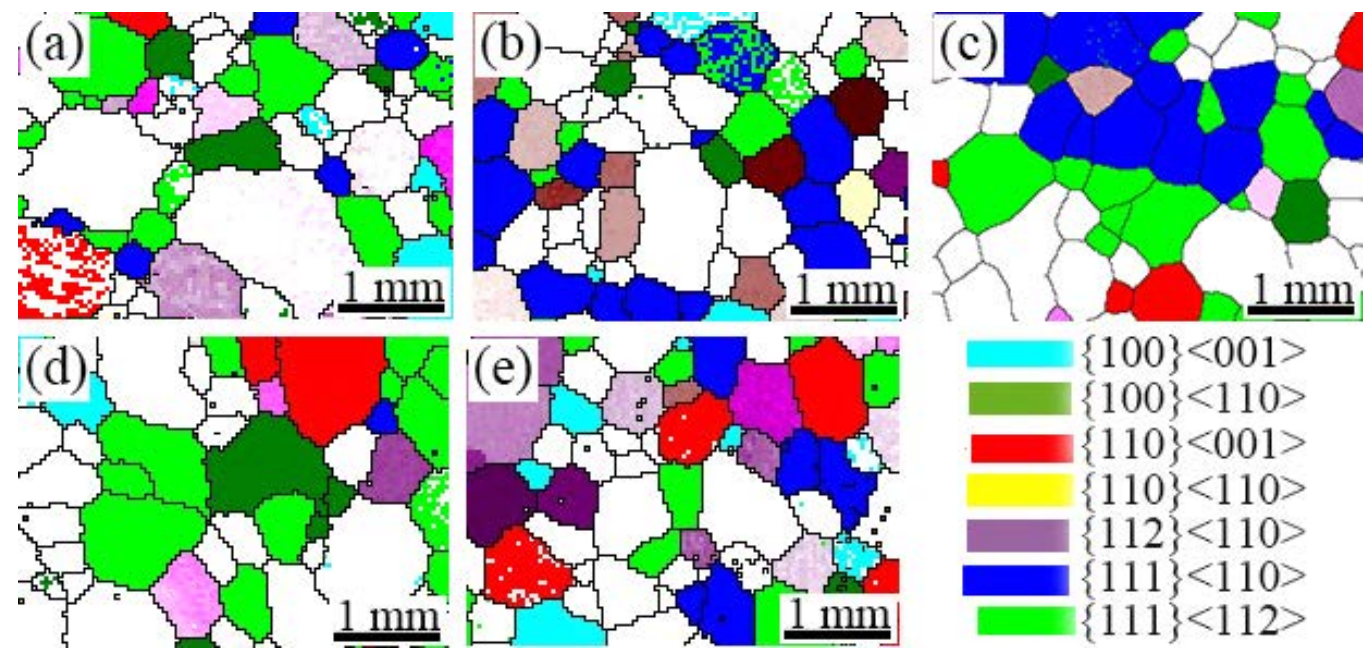

Fig. 4. Crystal orientation maps of final recrystallized microstructures at different Ag content: (a) $0 \mathrm{wt} \%$; (b) 0.003 $\mathrm{wt} \%$; (c) $0.005 \mathrm{wt} \%$; (d) $0.012 \mathrm{wt} \%$; (e) $0.026 \mathrm{wt} \%$. (Online version in color.)
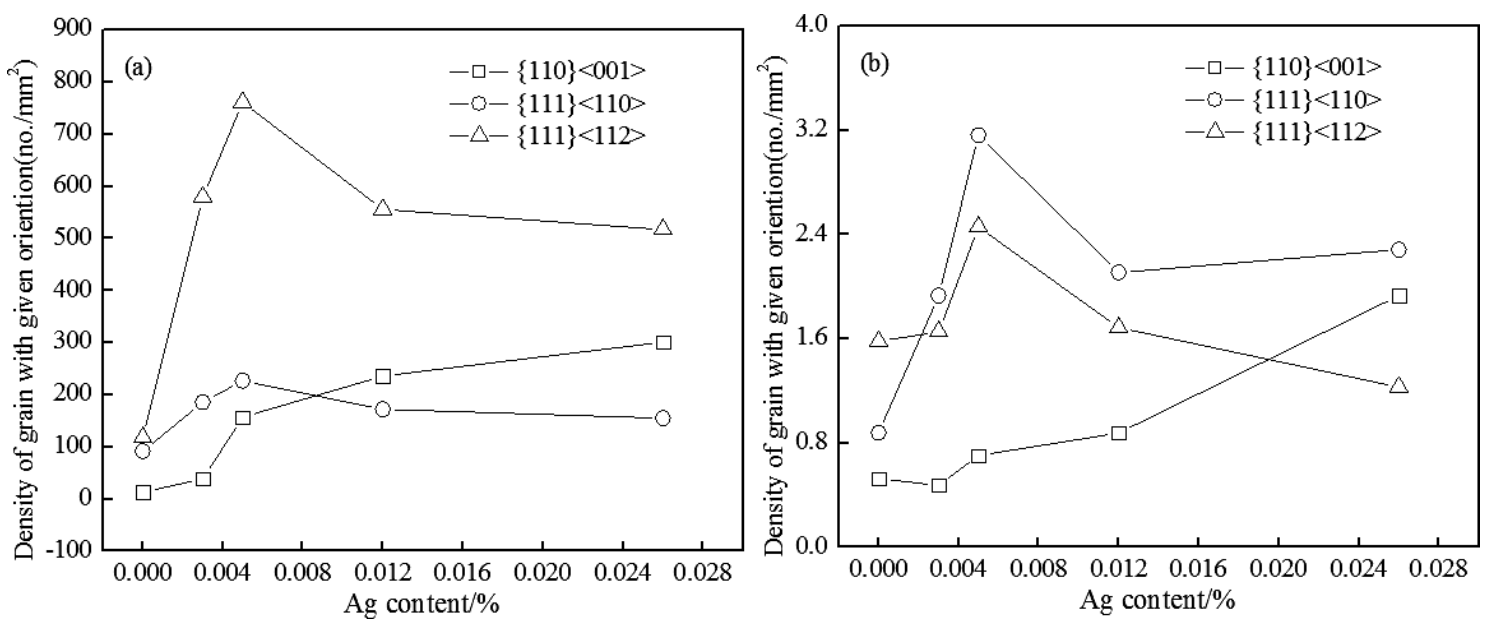

Fig. 5. Effect of Ag content on the density of grain with given orientation: (a) decarburized bands; (b) final recrystallized bands.

Table 2. Effect of Ag content on the average grain size of decarburized and final recrystallized bands.

\begin{tabular}{cccccc}
\hline Ag content $(\mathrm{wt} \%)$ & 0 & 0.003 & 0.005 & 0.012 & 0.026 \\
$\begin{array}{c}\text { Grain size of decarburized } \\
\text { bands }(\mu \mathrm{m})\end{array}$ & 43 & 31 & 26 & 18 & 13 \\
$\begin{array}{c}\text { Grain size of final } \\
\text { recrystallized bands }(\mu \mathrm{m})\end{array}$ & 401 & 417 & 432 & 443 & 399 \\
\hline
\end{tabular}

uniform than those in decarburized bands with Ag contents of $0 \mathrm{wt} \%, 0.003 \mathrm{wt} \%$ and $0.005 \mathrm{wt} \%$. As mentioned above, the main reason why the average grain sizes in decarburized bands with Ag contents of $0.003 \mathrm{wt} \%$ and $0.005 \mathrm{wt} \%$ are smaller than that in Ag-free decarburized bands is probably that the element of low solubility, such as Ag, segregates on the grain boundaries and retards the rate of boundary migration during grain growth of decarburizing. ${ }^{31)}$ There are also some ribbon-like grains in decarburized bands with Ag contents of $0.003 \mathrm{wt} \%$ and $0.005 \mathrm{wt} \%$. Tanaka et al. ${ }^{32)}$ reported that impurity atoms segregate at grain boundaries could result in that the coincidence site lattice (CSL) boundaries have lower grain boundary energies and higher migration mobility than general grain boundaries. Thus, during decarburizing, the abnormal growth of ribbon-like grains in decarburized bands with $\mathrm{Ag}$ contents of $0.003 \mathrm{wt} \%$ and $0.005 \mathrm{wt} \%$ is likely to be a combination of grains having CSL boundaries with adjacent grains. It can also be seen from Fig. 5(a) that the number of grains with $\{111\}<112>$ and $\{111\}<110>$ preferred orientations in decarburized bands with $\mathrm{Ag}$ contents of $0.003 \mathrm{wt} \%$ and $0.005 \mathrm{wt} \%$ is more than that in other decarburized bands. Burgers et al. ${ }^{33)}$ indicated that grains with $\{111\}<112>$ and $\{111\}<110>$ have higher dislocation densities and thus higher rates of subgrain growth and finally leading to $\{111\}$ nuclei on the grain boundary especially when the grain boundary energy is reduced. As stated earlier, Ag atoms only exist in the form of solid solution in low-Ag decarburized bands, hence, it is reasonable to assume that $\mathrm{Ag}$ atoms segregate on the grain boundaries and decrease the energy of the boundaries, and as a result, promote the nucleation rate of grain with $\{111\}$ orientation on the grain boundary in low-Ag decarburized bands. Furthermore, the number of grains with sharp $\{110\}<001>$ preferred orientation in high-Ag decarburized bands is more than that in low-Ag and Ag-free decarburized bands and the number of grains with $\{111\}<110>$ 
and $\{111\}<112>$ orientations decreases as Ag content increases from $0.005 \mathrm{wt} \%$ to $0.026 \%$ in decarburized bands (see Figs. 5(a), 7 and 9 ). It is also suggested that the grains with (111) orientation are nucleated in the vicinity of grain boundaries of the original hot rolled band ${ }^{34)}$ and thus the $\mathrm{Cu}$-rich particles precipitated on the grain boundaries might be responsible for retarding the nucleation of the grains with (111) orientation during the recrystallization annealing in non-oriented electrical steels. ${ }^{35)} \mathrm{Ag}$ is also one of the elements which precipitate as Ag-rich particles from the matrix, similar to copper. The precipitation of Ag-rich particles in the original hot rolled band is likely to inhibit the nucleation of the grains with (111) orientation during decarburizing annealing.

As shown in Fig. 4 and Table 2, the grains in final recrystallized band with a Ag level of $0.012 \mathrm{wt} \%$ are slightly larger than those in final recrystallized bands with Ag levels of $0 \mathrm{wt} \%, 0.003 \mathrm{wt} \%, 0.005 \mathrm{wt} \%$ and $0.026 \mathrm{wt} \%$, and the sizes of Ag-free final recrystallized band are still not uniform. It can also be seen that the density of grains with $\{110\}<001>$ preferred orientation in final recrystallized band with a Ag level of $0.026 \mathrm{wt} \%$ is largest than that in

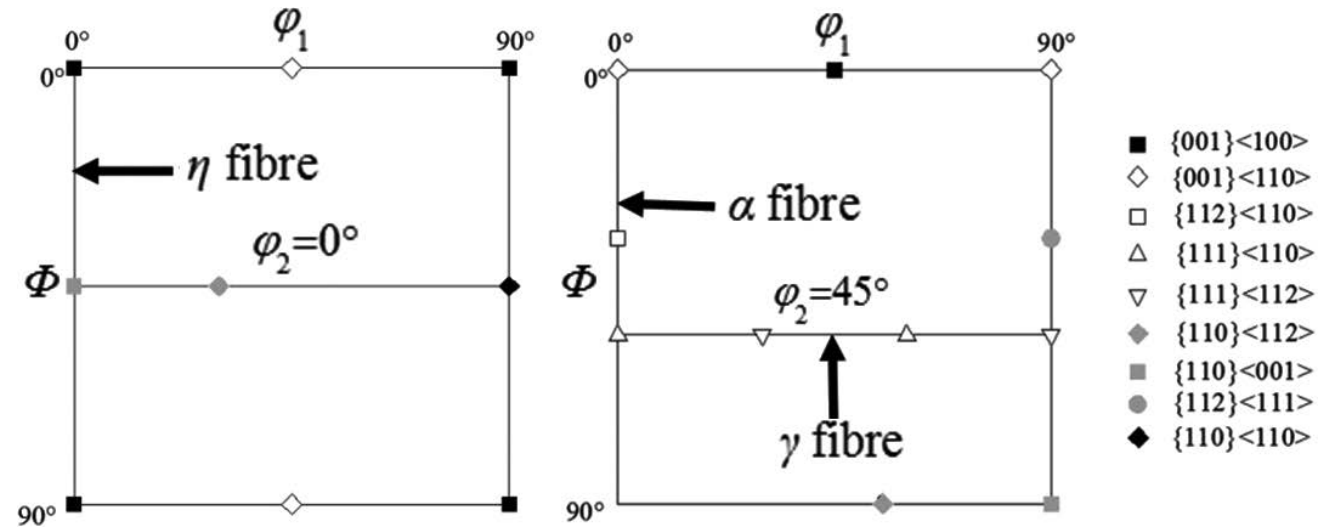

Fig. 6. Ideal preferred orientation in the Euler space in body centered cubic lattice.
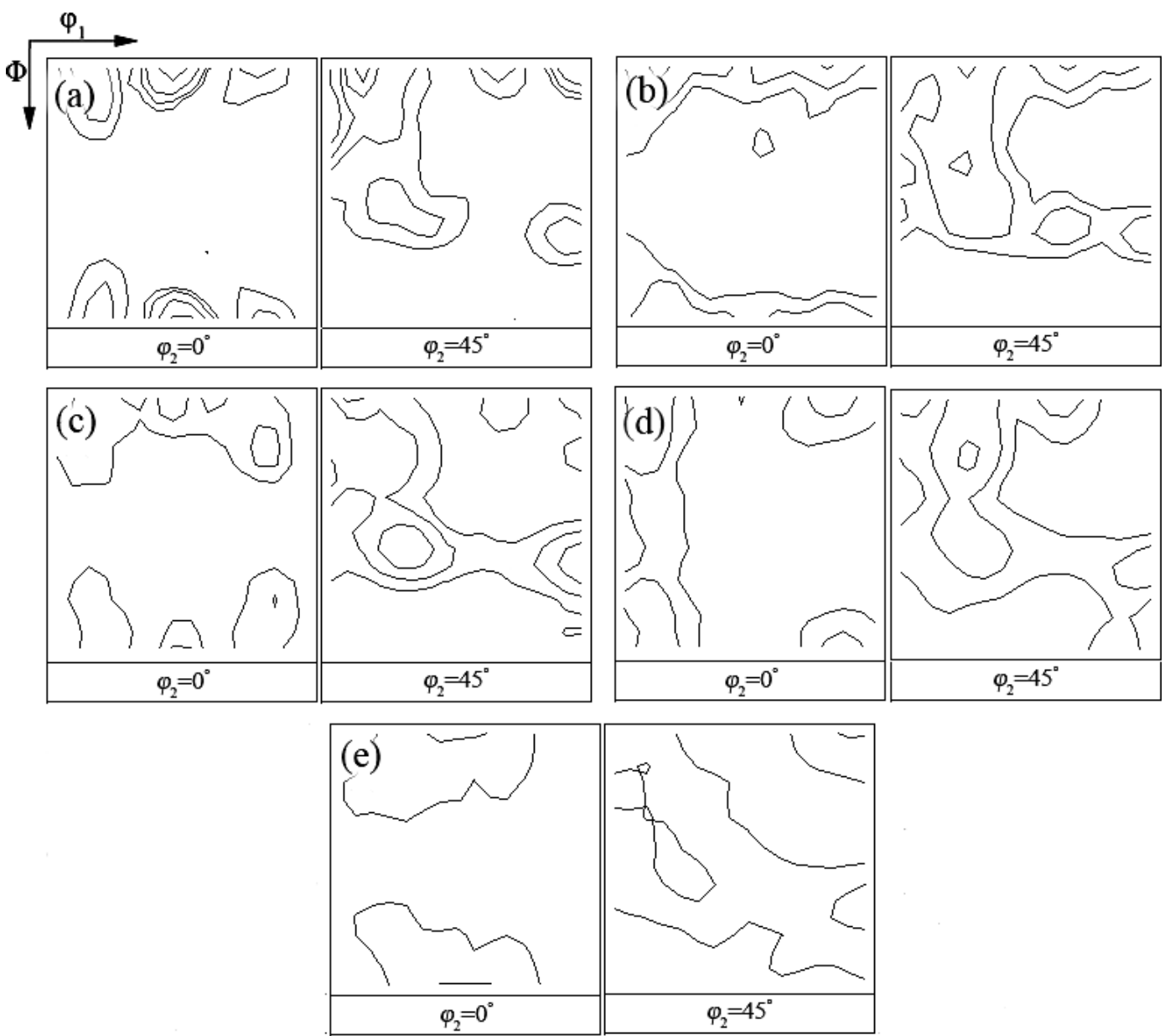

Fig. 7. ODF of decarburized bands at different Ag content: (a) $0 \mathrm{wt} \%$; (b) $0.003 \mathrm{wt} \%$; (c) $0.005 \mathrm{wt} \%$; (d) $0.012 \mathrm{wt} \%$; (e) $0.026 \mathrm{wt} \%$. 

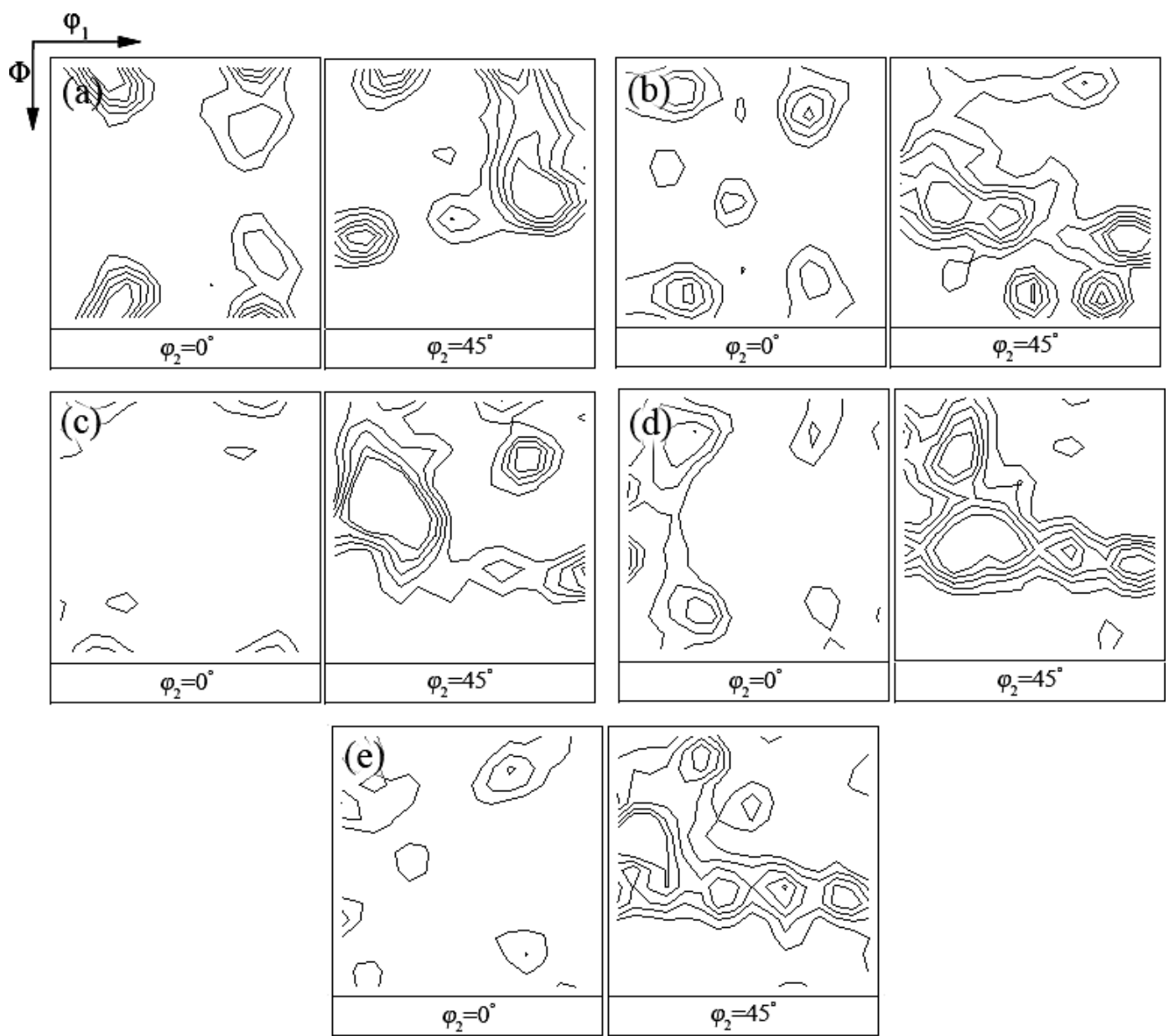

Fig. 8. ODF of final recrystallized bands at different Ag content: (a) $0 \mathrm{wt} \%$; (b) $0.003 \mathrm{wt} \%$; (c) $0.005 \mathrm{wt} \%$; (d) 0.012 wt $\%$; (e) $0.026 \mathrm{wt} \%$.
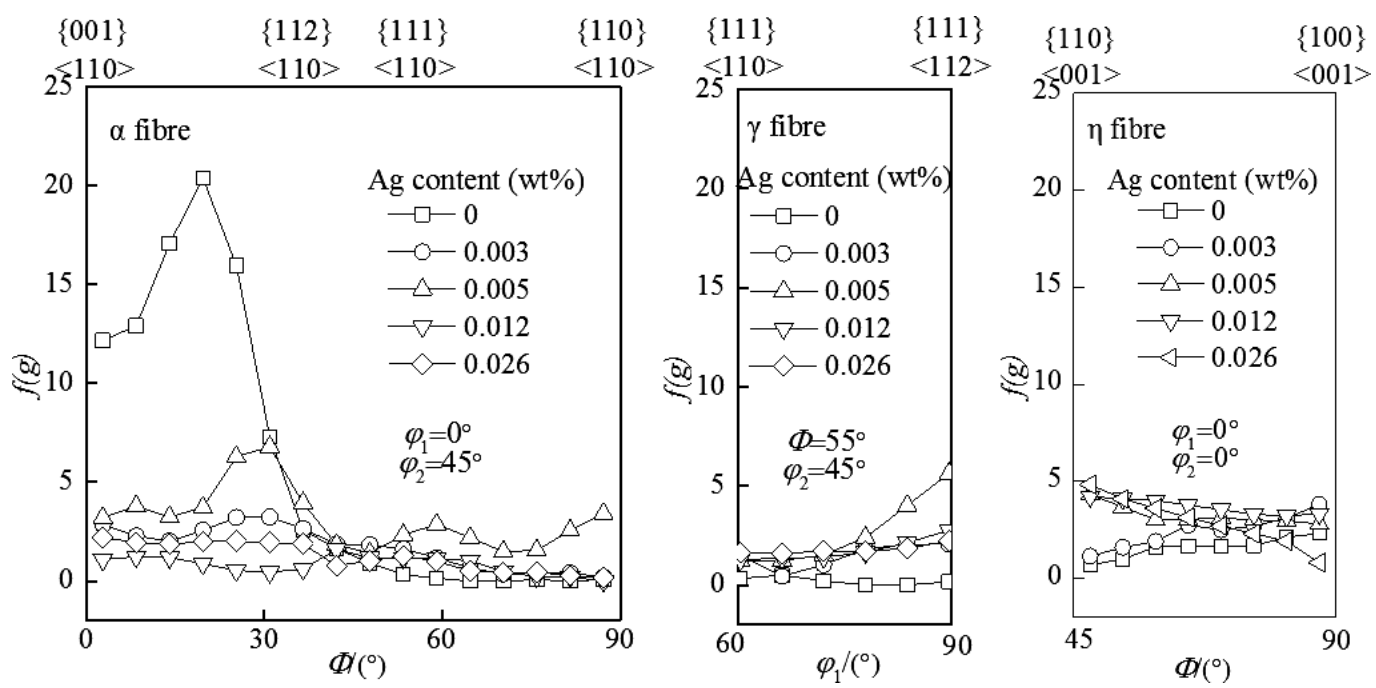

Fig. 9. Orientation distribution intensities of decarburized bands at different Ag content.

other final recrystallized bands from Figs. 5(b), 8 and 10, which is probably attributed to that the decarburized band with a Ag level of $0.026 \mathrm{wt} \%$ obtains the highest density of grains with $\{110\}<001>$ orientation, and as a result, lead to the largest number of Goss oriented grains grew up during secondary recrystallization annealing.

\subsection{Texture}

The main low index orientations of cubic structure materials in the Euler space are located at the orientation distribution function maps at $\varphi_{2}=0^{\circ}$ and $\varphi_{2}=45^{\circ}$ as shown in Fig. 6. ${ }^{36)}$ The effect of Ag content on the orientation distribution function of decarburized and final recrystallized bands is shown in Figs. 7 and 8. Figures 9 and 10 show the orientation distribution intensities of decarburized and final recrys- 

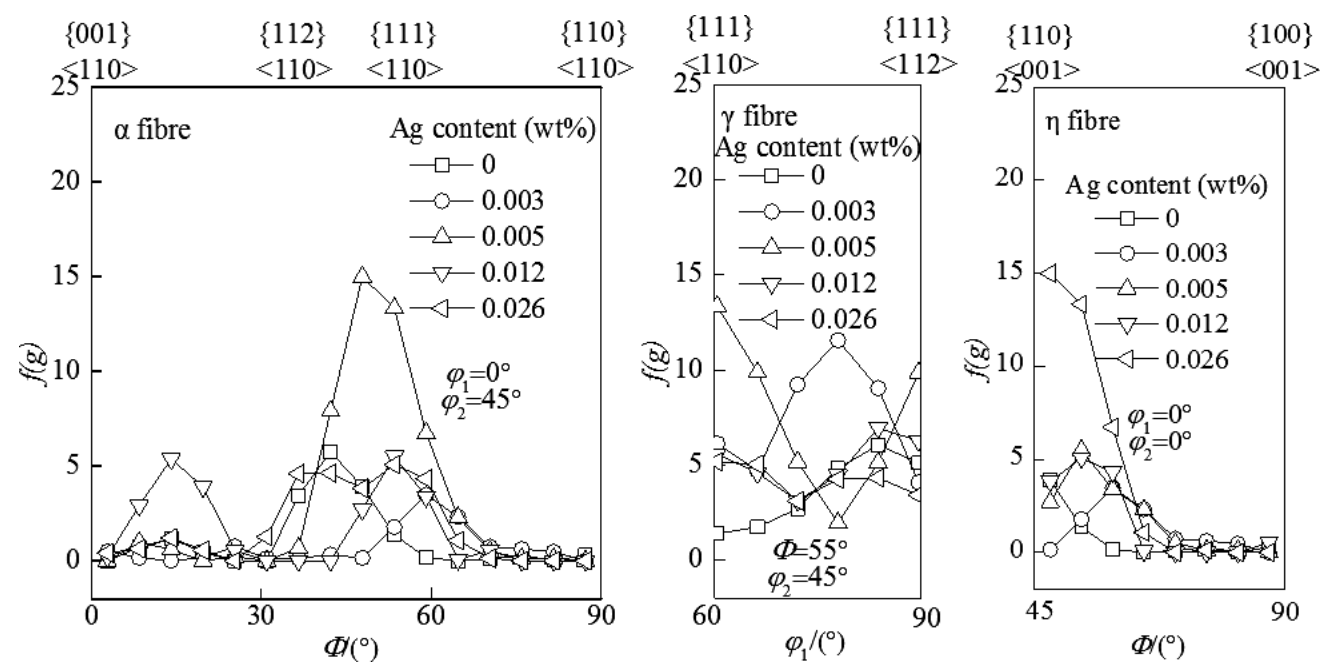

Fig. 10. Orientation distribution intensities of final recrystallized bands at different $\mathrm{Ag}$ content.

tallized bands at different $\mathrm{Ag}$ content. It can be observed from Figs. 7 and 9 that the intensities of $\{111\}<110>$ and $\{111\}<112>$ texture in decarburized bands firstly increase and then decrease with increasing Ag content and reach maximum values in in decarburized bands containing 0.005 wt $\%$ Ag. Figures 8 and 10 demonstrate that the final recrystallized bands with a Ag level of $0.026 \mathrm{wt} \%$ has the strongest intensity of $\{110\}<100>$ texture compared to the other recrystallized bands. It is found that the calculated texture data of decarburized and final recrystallized bands shown in Figs. $7-10$ is in good agreement with the crystal orientation maps of microstructures and the density of grain with given orientation presented in Figs. 3-5. Thus, it can be concluded that a small quantity of $\mathrm{Ag}$ atoms $(\leq 0.005 \mathrm{wt} \%)$ exists in the form of solid solution and promotes the nucleation rate of grain with $\{111\}$ orientation on the grain boundary during decarburizing process and, as a result, is conducive to the development of the $\{111\}$ texture component in decarburized and final recrystallized bands. However, an excess of $\mathrm{Ag}$ atoms $(\geq 0.012 \mathrm{wt} \%)$ precipitates as single Ag-rich phases and inhibits the nucleation of the grains with (111) orientation during decarburizing annealing and, hence, leads to that other texture components, such as $\{110\}<001>$ texture, achieve corresponding development during decarburizing and subsequent secondary recrystallization annealing.

\subsection{Magnetic Properties}

The effect of Ag content on the magnetic properties of final recrystallized bands in grain-oriented electrical steels is shown in Fig. 11. Under the same processing conditions, magnetic flux density $\left(B_{8}\right)$ firstly dramatically decreases and then abruptly increases with increasing Ag content, nevertheless, core loss $\left(P_{1.7 / 50}\right)$ firstly slightly increases and then obviously decreases with increasing Ag content. The final recrystallized band with a $\mathrm{Ag}$ level of $0.005 \mathrm{wt} \%$ achieves the worst magnetic properties, whose core loss and magnetic flux density are $1.384 \mathrm{~W} / \mathrm{kg}$ and $1.372 \mathrm{~T}$, respectively. The final recrystallized band containing $0.026 \mathrm{wt} \% \mathrm{Ag}$ obtains the best magnetic properties, whose core loss and magnetic flux density are $1.140 \mathrm{~W} / \mathrm{kg}$ and $1.467 \mathrm{~T}$, respectively.

Many factors, such as grain size, texture, impurities and inclusions affect the magnetic properties of electrical steels.

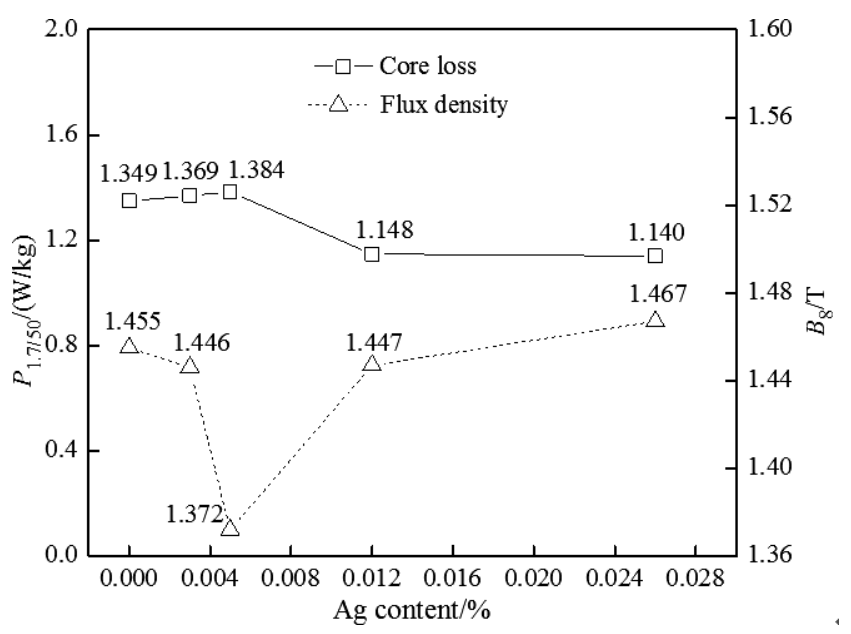

Fig. 11. The magnetic properties of final recrystallized bands at different Ag content.

Both magnetic flux density and core loss of grain-oriented electrical steels are strongly affected by their texture. Goss grain has $<001>$ easy magnetization axis in the rolling direction and this is beneficial to the magnetic properties. In contrast, $\{111\}\langle u v w>$ fiber textures do not possess $<001>$ easy magnetization axis in the rolling direction and this is deleterious to the magnetic properties. As stated in the previous section, the area percentage of $\{111\}<u v w>$ in the final recrystallized band with $0.005 \mathrm{wt} \% \mathrm{Ag}$ is stronger than that in the other final recrystallized bands, and thus obtains the worst magnetic properties. As stated above, the very fine $(<1 \mu \mathrm{m})$ Ag-rich particles in the final recrystallized band containing $0.026 \mathrm{wt} \% \mathrm{Ag}$ is more than that in the other final recrystallized bands. It has been reported that the very fine precipitates impedes domain movement during magnetization and are harmful to the hysteresis loss and core loss of electrical steel. ${ }^{37)}$ However, the final recrystallized band containing $0.026 \mathrm{wt} \% \mathrm{Ag}$ which has the strongest Goss texture achieves the lowest core loss and the highest magnetic flux density. Thus, it can be concluded that the effect of Goss texture on the core loss is more pronounced than Ag-rich particle. 


\section{Conclusion}

The effect of $\mathrm{Ag}$ content from 0 to $0.026 \mathrm{wt} \%$ on the precipitates, microstructure, texture and magnetic properties of grain-oriented silicon steels has been studied. The results can be summarized as below:

(1) $\mathrm{Ag}$ atoms only exist in the form of solid solution with Ag content less than $0.005 \mathrm{wt} \%$, nevertheless, some supersaturated $\mathrm{Ag}$ atoms will precipitate from the matrix and in the form of single Ag-rich particles when Ag level rises to $0.012 \mathrm{wt} \%$. Ag atoms are less prone to form $\mathrm{Ag}_{2} \mathrm{~S}$ precipitates in the grain-oriented silicon steel.

(2) The average grain size of decarburized bands decreases continuously as $\mathrm{Ag}$ content rises from 0 to 0.026 wt $\%$. Compared to those final recrystallized bands with other Ag contents, the final recrystallized bands containing $0.012 \mathrm{wt} \% \mathrm{Ag}$ obtains slightly larger average grain size.

(3) Ag in solid solution in grain-oriented silicon steel promotes the nucleation rate of grain with $\{111\}$ orientation on the grain boundary during decarburizing process. Ag-rich particle is to the benefit of inhibiting the nucleation of the grains with (111) orientation and, as a result, promoting the nucleation of grains with other orientation, such as Gossorientation, during decarburizing process.

(4) Under the same processing conditions, As Ag content rises from 0 to $0.026 \mathrm{wt} \%$, magnetic flux density $\left(B_{8}\right)$ firstly dramatically decreases and then abruptly increases, nevertheless, core loss $\left(P_{1.7 / 50}\right)$ firstly slightly increases and then obviously decreases in final recrystallized bands. Final recrystallized band with $0.026 \mathrm{wt} \% \mathrm{Ag}$ obtains the best magnetic properties, whose core loss and magnetic flux density are $1.140 \mathrm{~W} / \mathrm{kg}$ and $1.467 \mathrm{~T}$, respectively.

\section{REFERENCES}

1) Z. Z. He, Y. Zhao and H. W. Luo: Electrical Steel, Metallurgical Industry Press, Beijing, (2012), 85.

2) N. Takahashi, Y. Suga and H. Kobayashi: J. Magn. Magn. Mater., 160 (1996), 98

3) N. Takahashi and J. Harase: Mater. Sci. Forum, 204-206 (1996), 143.
4) T. Kubota, M. Fujikura and Y. Ushigami: J. Magn. Magn. Mater., 215-216 (2000), 69

5) Y. Ushigami, M. Mizokami, M. Fujikura, T. Kubota, H. Fujii and K. Murakami: J. Magn. Magn. Mater., 254-255 (2003), 307.

6) S. T. Qiu, L. Xiang, E. B. Yue and P. Zhao: Iron Steel, 43 (2008), 2.

7) H. Honma, Y. Ushigami and Y. Suga: J. Appl. Phys., 70 (2008), 6259.

8) J. Harase, R. Shimizu and D. J. Dingley: Acta. Metall. Mater., 39 (1991), 763.

9) M. Matsuo: ISIJ Int., 29 (1989), 809.

10) T. Obara, H. Takeuchi, T. Takamiya and T. Kan: J. Mater. Eng. Perform., 2 (1993), 205.

11) J. W. Flowers: IEEE. Trans. Magn., 15 (1979), 1601.

12) S. Turner, A. Moses, J. Hall and K. Jenkins: J. Appl. Phys., 107 (2010), 307.

13) Y. Yoshitomi, K. Iwayama, T. Nagashima, J. Harase and N. Takahasi: J. Jpn. Inst. Met., 55 (1991), 630.

14) T. H. Shen: J. Mater. Eng., 11 (1989), 71.

15) J. Keith and L. Magnus: J. Magn. Magn. Mater., 320 (2008), 2423.

16) Z. Z. He, Z. F. Liu, B. C. Zhang and W. R. Zhang: Acta Metall. Sin., 29 (1993), 496.

17) N. Bernier, C. Xhoffer, T. V. D. Putte, M. Galceran and S. Godet: Mater. Charact., 86 (2013), 116.

18) C. C. Liao and C. K. Hou: J. Magn. Magn. Mater., 322 (2010), 434.

19) T. Kumano, T. Haratani and N. Fujii: ISIJ Int., 45 (2005), 95.

20) C. C. Chen and C. K. Hou: CAMP-ISIJ, 23 (2010), 186, CD-ROM.

21) T. Sakai, M. Shiozaki and K. Takashina: J. Appl. Phys. B, 50 (1979), 2369.

22) Z. Z. Liu, Y. Kobayashi and K. Nagai: ISIJ Int., 44 (2004), 1560.

23) L. Xiang, E. B. Yue, S. T. Qiu and P. Zhao: Iron Steel, 44 (2009), 79.

24) Y. Zhao, Z. Z. He, J. Zhu, Y. Q. Weng and B. R. Wu: Acta Metall. Sin., 29 (1993), 496.

25) S. Mishra and V. Kumar: Mater. Sci. Eng. B, 32 (1995), 177

26) Z. F. Liu, Z. B. Liu, J. Li and Z. Z. He: Acta Metall. Sin., 27 (1991), 282.

27) T. Saito: J. Jpn. Inst. Met., 27 (1963), 191.

28) M. Imai: Tetsu-to-Hagané, 58 (1972), 2102.

29) E. J. Fitz: Silicon Steel with Improved Magnetic Anisotropy and Method of Making the Same. US Patent 2913361, (1959).

30) M. Takashima: High-Silicon Steel Sheet with Excellent HigeFrequency Core Loss Characteristic, and Its Manufacturing Method, JP Patent 066894, (2005).

31) T. Saito: J. Jpn. Inst. Met, 27 (1963), 186

32) I. Tanaka and H. Yashiki: ISIJ Int., 47 (2007), 1666.

33) W. G. Burgers and P. C. Louwerse: Z. Phys., 67 (1931), 605

34) M. F. Rodrigues, M. A. Da Cunha, S. Da Costa Paolinelli and A. B. Cota: J. Magn. Magn. Mater., 331 (2013), 24.

35) X. H. Bian, Y. P. Zeng, D. Nan and M. Wu: J. Alloy. Compd., 588 (2014), 108

36) W. M. Mao and X. M. Zhan: The Quantitative Analysis of Texture in Crystal Material, Metallurgical Industry Press, Beijing, (1995), 61.

37) I. Boc, A. Cziraki, T. Grof and J. Csebi: J. Magn. Magn. Mater., 83 (1990), 381 